\title{
Looking for a pointed role
}

The annual meeting of the British Association promises to be better than usual but the perennial problem of the association's proper function persists.

BY the unexciting standards set in recent years, this year's annual meeting of the British Association for the Advancement of Science promises well. No doubt the venue helps - a sea-coast university is bound to give many of the participants a sense of being on holiday - but the University of Sussex has obviously been stung by its vice-chancellor's inclination to send the association packing off elsewhere into dredging into its liberal origins both to provide some interesting topics for discussion as well as a child-minding service for the benefit of participants. Fortunately, the meeting is also contained within a working week, which is convenient for those attending and which means that no bishop will be tempted to preach a sermon for the occasion, as used to be the custom. (There is no cathedral within convenient distance, in any case.) And this year the management of the British Association has taken steps that may eventually help to remedy one of the obvious defects of these occasions during recent decades the virtual absence of up-to-date science from the usual agenda. This has been done, by persuading a number of learned and professional societies to provide symposia not merely for their own members but for those of the British Association as well. Let us hope that this and the other bright sparks in this year's programme somehow survive.

Meanwhile, the association still has to decide what its function should be. For far too long, since it ceased in the 1920 s to be the kind of professional society that the nineteenth century had needed, the association has been the prisoner of uniformity of purpose. Too often, it has behaved as if its continued existence would in itself be sufficient - and then has found that the funds that kept it going (now mostly from the government under the umbrella of the Royal Society) were likely to dry up. When, in the late $1960 \mathrm{~s}$, the association was acutely faced with the risk of having to go out of business, the notion that other learned societies could usefully be asked to help enliven the annual meetings was widely canvassed, universally approved - and then forgotten. At that time, the association also embarked on a plan to carry out studies of public issues with important scientific connotations, but in the past fifteen years that plan has been pursued with only fitful vigour. There have been several attempts to mount public discussions of important public issues uncluttered with the rituals of the annual meetings, but these have been too few, and too uneven in quality, to point unambiguously to a new role for the association as a whole. And the admirable idea that the association might create some kind of publication that would give it a wider claim on public attention (and help to keep the wolf from the door as well) has not been diligently pursued.

\section{Management}

These are all familiar problems to those acquainted with the association. The reason they persist is also plain. The British Association is poorly managed, and the reasons for that are constitutional, not personal. Presidents vary, but even those interested in helping to get something done are there only for a year. Otherwise responsibility for policy rests with a cumbersome council, while the execution of policy is shared between an army of often autonomous volunteers and a tiny staff which is not encouraged to have ideas of its own. The results are plain in the patchiness of the programme for the annual meetings. This year, for example, there are planned both a possibly absorbing sym- posium on the technology of satellite communications and a talk with the curious title "Biotechnology: the way ahead for botanists".

Although both the annual symposia and much of the associations other undertakings are characterized by a homespun parochialism that is no longer endearing, the association has a great deal of goodwill that it could draw on. While affection for such an old and interesting organization is no longer bankable in financial terms, it is an asset that cannot be ignored. People are willing to do what they can for the British Association (which is, indeed, how it rubs along at present). Moreover, the association has by good fortune retained among British newspapers the reputation of being a place at whose annual meetings it is possible to pick and retail to readers an account of where science stands; the fact that there tends to be little else in the way of news at this time of the year no doubt helps to ensure an uncritical appraisal of this use of resources. Then there are the people who turn up at meetings (which evidently give great pleasure) whose loyalty gives the association its annual injection of the conviction that it is doing a good job, not to mention those who are cajoled into speaking on topics of somebody else's choice, but who must usually pay their travelling expenses to do so: these and many other groups of people keep the association going, but will not do so indefinitely.

\section{The future}

To be sure about its future, the association must therefore find both a clearer concept of what it is for and a more secure means of organizing its affairs efficiently. As to its roles, there are three matters that the association should attend to, chief of which is to devise a policy. Unlike other bodies - most learned societies for example - the British Association is not prevented by its constitution from having views on questions such as the appalling arrangements for science education in Britain, the way in which research money is shared out and the suitability of British universities for the remainder of this century. To advocate that the association should develop policies for the sake of having them would of course be ridiculous, but these are all questions on which too much is decided behind closed doors, and on which independent views, publicly expressed, are in short supply. Second, the association needs to be a more effective vehicle for doing what it purports to be doing at present - providing a platform for British scientists to tell a wider public what they are up to. As budgets have been tightened and as the competition with people elsewhere has intensified, the usual reticence has given way to an eagerness to talk in public (which would serve the public interest). Third, given the association's objects and the absence of comparable informal academies elsewhere in Europe, there is a chance that the association could do a useful job if it spread its wings more widely in Western Europe. At least it would be worth a try.

The snag, it will be said, is that none of these things will be possible unless there is a stronger professional organization, which will take money, and that there is no prospect of more money coming along until the association has been able to show that it is able to perform a unique public service of some kind. But this is a recipe for getting nowhere. And the argument is false. It might suffice if the association were simply to make up its mind what kind of animal it wants to be. 